\title{
Superior Mechanical Properties of SWCNT Incorporated Borosilicate Glass Composite
}

\author{
Sujan Ghosh* \\ Advanced Ceramics $\&$ Composites Division, \\ CSIR - Central Glass \& Ceramic Research Institute, \\ Jadavpur, Kolkata - 700032, India
}

\begin{abstract}
The conventional melt-quench technique was employed for the fabrication of single walled carbon nanotube (SWCNT) - borosilicate glass composite. Reduced Young's modulus $\left(\mathrm{E}_{\mathrm{r}}\right)$ and Brittleness index (B) were evaluated using indentation method both for the borosilicate glass and the SWCNT incorporated borosilicate glass composite. $\mathrm{E}_{\mathrm{r}}$ value of the composite was higher compared to the base glass. On the other hand the composite shows lower brittleness index than that of the base glass where the reduction was more prominent in the higher load. However, those interesting properties of the composite were explained by the existence of mechanically robust SWCNTs and their different characteristics.
\end{abstract}

\section{INTRODUCTION}

Carbon nanotubes encouraged a lot of researchers by their excellent physical properties [1] in the last decade. Material scientists, who were involved in the search of a new composite material surely select the carbon nanotubes since they have the capability to change the basic properties of a material in terms of mechanical, thermal and electrical parameters. Among those properties, the different mechanical parameters of carbon nanotubes and their behaviour in a composite material were discussed in numerous reports where some approaches were failed to improve the performance of the fabricated composite compared to the base material. Polymers and metals [2, 3] were mostly used as the base material for the synthesis of the CNT- composite which can observed in various papers. In contrast, there were comparatively few reports where ceramics and glasses [4] were used as a base material to made-up CNT based composites. However, if one can start the discussion of brittle materials then glass is the obvious choice. Many researches were involved in reducing the brittleness of glass without hindering its other fascinating properties like optical, dielectric etc.

In this report, two relatively uncommon mechanical parameters namely reduced Young's modulus and Brittleness index of the borosilicate glass and the SWCNT incorporated glass-composite were thoroughly discussed. Furthermore, the behaviour of nanotubes in the environment of the glass host was investigated and how the nanotubes control those mechanical parameters was described.

\section{MATERIALS AND METHODS}

$60 \%$ pure single walled carbon nanotubes were purchased from Arry, Germany having length: 5-20 $\mu \mathrm{m}$;

\footnotetext{
* sujanghosh80@gmail.com
}

outer diameter: 1-2 nm; special surface area: $>400 \mathrm{~m}^{2} / \mathrm{g}$. Approximately $0.3-0.4 \mathrm{~g}$ of SWCNT was well blended with the mixture of aniline and toluene and finally this mixture was heated with reflux. The heating was stop when the solution became dark brown [5]. Very small frits of borosilicate glass were chosen as the base material with the following chemical composition: $\mathrm{SiO}_{2}-$ $69.2 \%, \mathrm{~B}_{2} \mathrm{O}_{3}-10 \%, \mathrm{BaO}-3 \%, \mathrm{~K}_{2} \mathrm{O}-8.4 \%, \mathrm{Na}_{2} \mathrm{O}-$ $8.4 \%, \mathrm{CeO}_{2}-0.53 \%$. Two important parameters namely the glass transition temperatures $\left(\mathrm{T}_{\mathrm{g}}\right)$ and the softening point of the chosen glass was found to be $567^{\circ} \mathrm{C}$ and $717^{\circ} \mathrm{C}$ respectively. About $2.5 \mathrm{~g}$ of fritted glass was well mixed with a certain volume of the dark brown solution in a crucible. The prepared mixture is then placed in an atmospheric controlled furnace for melting. The furnace maintains the temperature range $790-810^{\circ} \mathrm{C}$ for one hour at argon atmosphere during melting. To avoid crystallization the sample is then rapidly cooled to room temperature.

After fabricating the composite some rectangular plate shaped sample were cut and optically polished to evaluate mechanical parameters. For this reason Vicker's and Knoop micro indentation (Model no: Leco LH 700) was carried out with loads $0.1 \mathrm{~N}, 0.15 \mathrm{~N}, 0.2 \mathrm{~N}, 0.25 \mathrm{~N}, 0.5 \mathrm{~N}$ and $1 \mathrm{~N}$.

To analyse the existence and distribution of the carbon nanotubes in the composite the HRTEM and the SEM analysis were done.

\section{RESULTS AND DISCUSSION}

Reduced Young's Modulus ( $\left.\mathbf{E}_{\mathbf{r}}\right)$ : Young's modulus (E) is an important mechanical property [6] which actually measures how much a material resist itself from the deformation under the applied external stress. Now in indentation process, when the indenter and the material are in contact, there must be some sort of deformation in the indenter. So, keeping view of this fact the $\mathrm{E}_{\mathrm{r}}$ value is more effective than the $\mathrm{E}$ value during indentation. Considering the following equation the $\mathrm{E}_{\mathrm{r}}$ values of the glass 
and the composite were calculated.

$$
\frac{1}{E_{\mathrm{r}}}=\frac{1-\nu^{2}}{E}+\frac{1-\nu_{\mathrm{i}}^{2}}{E_{\mathrm{i}}}
$$

In the right hand side of the equation $1 \mathrm{E}, \nu$ and $\mathrm{E}_{\mathrm{i}}, \nu_{\mathrm{i}}$ are the Young's modulus and the Poission's ratio of the specimen and the indenter respectively. However, the $\mathrm{E}_{\mathrm{r}}$ values of the borosilicate glass and the composite were found to be $81.27 \mathrm{GPa}$ and $86.99 \mathrm{GPa}$ respectively. One can observe the increment of $\mathrm{E}_{\mathrm{r}}$ value in the composite which indicate the composite material performs better than the base glass under the external stress. To measure the $E$ values of the base glass and the composite the Vicker's and Knoop indentation techniques were employed.



FIG. 1. Brittleness index vs. Load graph

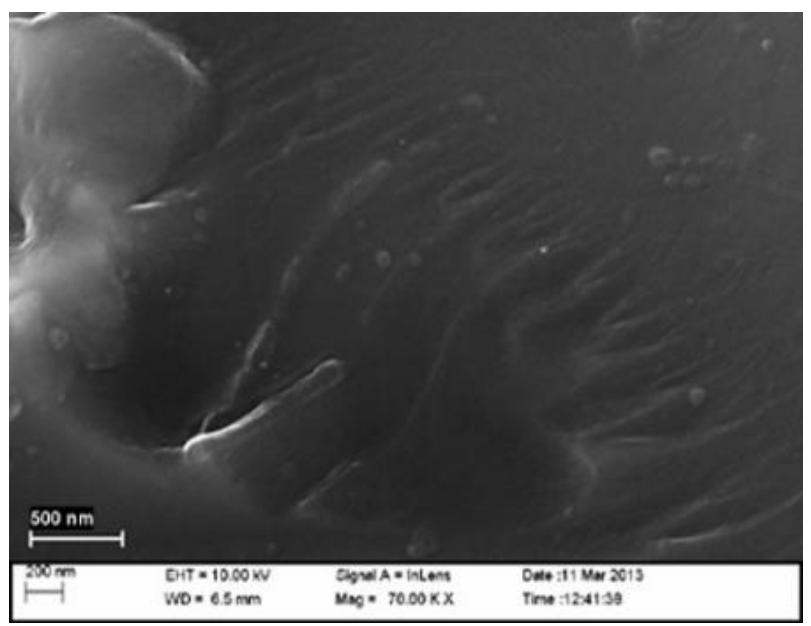

FIG. 2. SEM image shows the entanglement of SWCNT bundles

Brittleness index (B): It is another important mechanical parameter determining the failure characteris- tics of a material upon loading and unloading. According to Lawn and Marshall, brittleness is one of the elusive mechanical properties [7] which measure the competition between deformation and fracture under indentation. The brittleness indices of the base glass and the composite were evaluated by the ratio $\mathrm{H} / \mathrm{K}_{\mathrm{ic}}$, where $\mathrm{H}$ is the hardness and $K_{i c}$ is the fracture toughness measured in the Vicker's indentation method. Since in this work external loads were varied from lower to moderately higher value, the $H$ values were changed and also $B$ values were changed accordingly. The plot of brittleness index vs. load is depicted in Figure 1 where the B values were lower in composite than the glass for all the applied loads. Meticulous observation of Figure 1 also shows that the decrement of $B$ value was more prominent in the higher loads. This fact was understandable when one can see the microstructural images (SEM and HRTEM) of the SWCNT incorporated borosilicate glass composite.

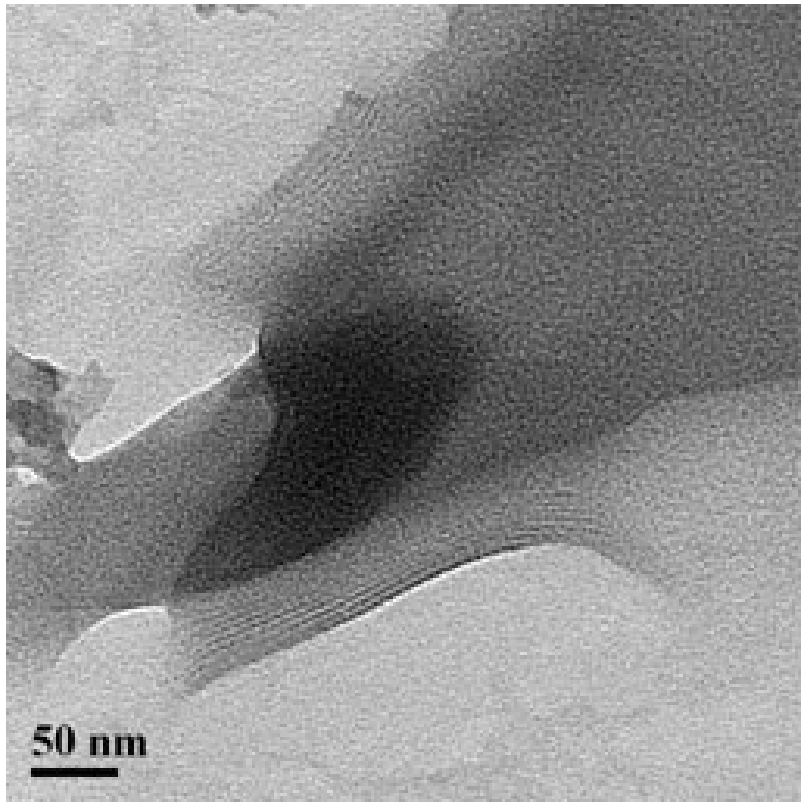

FIG. 3. HRTEM image shows regular arrangement of SWCNTs inside a bundle

Figure 2 shows the SEM image of the composite where one can see carbon nanotube bundles were haphazardly distributed throughout the glass. Further investigation of a single bundle was carried out through HRTEM which represents in Figure 3. In this figure beautiful arrangement of individual SWCNTs was observed inside a bundle. So, the existence and distribution of SWCNTs in the composite was confirmed by figures 2 and 3 . Actually the entangled SWCNT bundles act as high pressure cushion 8 10 and reduced the diagonal length of the indentation impression and also the crack length in the composite than the base glass. This cushioning phenomenon of entangled SWCNT bundles is the prime reason of enhanced $\mathrm{E}_{\mathrm{r}}$ value and reduced $\mathrm{B}$ value of the composite. At the low loads the indenter was confined mostly in the surface 
region where trivial effect of cushioning occurred, but as the load increases indenter was entered much inside and cushioning phenomenon became predominant. For this reason, the decrement of $B$ value in the composite was more at higher loads region.

\section{CONCLUSION}

One of the main objective in the CNT-composite based research works is that the fabricated composite should mechanically strong so that it can be used for different modern applications. The structural aspect of a material plays very crucial role whatever be the actual intention of the researches to use them in a specific purpose. Here, in this work, two important mechanical parameters were enhanced compared to the base material instead of using low loading (almost 2 wt \%) of SWCNTs in the composite. The enhanced $\mathrm{E}_{\mathrm{r}}$ value and the reduced brittleness of the composite make it a promising material for different structural applications like electromagnetic interface shielding, aerospace engineering etc. Though this types of end-use production needs further rigorous research and amalgamation of both science and technology in a certain direction.
[1] M. J. Treacy, T. W. Ebbesen, and J. M. Gibson, Exceptionally high young's modulus observed for individual carbon nanotubes, nature 381, 678 (1996).

[2] L. Schadler, S. Giannaris, , and P. Ajayan, Load transfer in carbon nanotube epoxy composites, Applied physics letters 73, 3842 (1998).

[3] R. George, K. Kashyap, R. Rahul, and S. Yamdagni, Strengthening in carbon nanotube/aluminium (cnt/al) composites, Scripta Materialia 53, 1159 (2005).

[4] A. Mukhopadhyay, B. T. Chu, M. L. Green, and R. I. Todd, Understanding the mechanical reinforcement of uniformly dispersed multiwalled carbon nanotubes in alumino-borosilicate glass ceramic, Acta Materialia 58, 2685 (2010).

[5] A. Ghosh, S. Ghosh, S. Das, P. Das, D. Majumder, and R. Banerjee, Synthesis and electrical properties of a single walled carbon nanotube-borosilicate glass composite, Chemical Physics Letters 496, 321 (2010).

[6] Y. P. Cao, X. Q. Qian, and J. Lu, On the determination of reduced young's modulus and hardness of elastoplastic materials using a single sharp indenter, Journal of materials research $\mathbf{2 1}, 215$ (2006).

[7] B. Lawn and D. Marshall, Hardness, toughness, and brittleness: an indentation analysis, Journal of the American ceramic society $\mathbf{6 2}, 347$ (1979).

[8] T. Wei, K. Wang, Z. Fan, J. Yan, W. Qian, and F. Wei, Super resilience of a compacted mixture of natural graphite and agglomerated carbon nanotubes under cyclic compression, Carbon 48, 309 (2010).

[9] C. Cao, A. Reiner, C. Chung, S.-H. Chang, I. Kao, R. V. Kukta, and C. S. Korach, Buckling initiation and displacement dependence in compression of vertically aligned carbon nanotube arrays, Carbon 49, 3190 (2011).

[10] S. Ghosh, A. Ghosh, T. Kar, S. Das, P. K. Das, and R. Banerjee, Cushioning effect, enhanced localized plastic flow and thermal transport in swcnt-lead silicate glass composite, Chemical Physics Letters 547, 58 (2012). 